\title{
Caminhos (des)regrados, desejos volúveis: etnografia noturna de uma feira livre numa cidade amazônica
}

\author{
Cassio José Sousa Silva \\ Programa de Pós-graduação em Linguagens e Saberes na \\ Amazônia \\ Universidade Federal do Pará \\ Flavio Leonel Abreu da Silveira \\ Programa de Pós-Graduação em Sociologia e Antropologia \\ Universidade Federal do Pará
}

Resumo: Este artigo trata de apresentar os cenários de sociabilidade urbana onde figuram homens com interesses e práticas afetivo-sexuais, que são destinadas a pessoas do mesmo sexo. Para tanto, o seu foco volta-se à feira livre da cidade de Bragança, região do nordeste paraense. Problematiza-se, desta forma, alguns pontos centrais para a discussão sobre a produção da cidade e seus espaços urbanos pela via do exercício da sexualidade, destacando-se a noite como cenário dos devires e das perambulações dos sujeitos. Interessa-nos o tempo da profusão de desejos que criam espaços da sexualidade, ou seja, espaços da fluência dos desejos e cenários de negociações entre diversos personagens.

Palavras-chave: sociabilidade; modos de vida; desejo; sexualidade. 


\title{
(Un)reasonable paths and voluble desires: A nocturnal ethnographic study of a street market in an urban Amazon space
}

\begin{abstract}
This article presents urban social interactions in which men's affective sexual practices are directed towards other men. The area of study is the street markets of the city of Bragança, located in the northeastern corner of the state of Pará. A series of points is discussed involving the livelihood of the city and its urban spaces and to what degree they allow one to exercise their sexuality, highlighting the night as a scene as transformations and perambulations of the subjects. Of special interest is the time of profusion of desires that create sexual spaces, or, in other words, spaces that incite desires and in which sexual exchanges are made.
\end{abstract}

Keywords: sociability; way of life; desire; sexuality.

\section{Caminos (des)regrados, deseos inconstantes: etnografía nocturna de un mercado libre en una ciudad amazónica}

Resúmen: Este artículo presenta los escenarios de sociabilidad urbana que incluyen hombres con intereses y prácticas afectivo-sexual dirigidos a las personas del mismo sexo. Por lo tanto, el foco se vuelve al mercado libre en la ciudad de Bragança, en el noreste de Pará. Tratamos, de esta manera, algunos puntos centrales para la discusión de la producción de la ciudad y sus espacios urbanos por medio de la sexualidad, destacando la noche como escenário de los devenires y andanzas de los sujetos. Estamos interesados en el momento de la multitud de deseos que crean espacios de la sexualidad, es decir, los espacios de fluidez de los deseos y escenarios de negociación entre los distintos personajes.

Palabras clave: sociabilidad; formas de vida; deseo; sexualidad. 


\section{Introdução}

As reflexões aqui apresentadas compõem parte da dissertação de mestrado defendida no âmbito do Programa de Pós-Graduação em Linguagens e Saberes na Amazônia (PPGLSA/UFPA), que investigou os modos de organização social, cultural, e político presente em cenários onde transitam homens que vivenciam práticas eróticas, afetivas e sexuais com o mesmo sexo.1

Tendo como cenário principal uma feira livre, a pesquisa foi realizada na cidade de Bragança. Historicamente a cidade, pela sua localização geográfica, ocupa um lugar de destaque na economia e política do estado do Pará. Sendo um dos primeiros polos de colonização nesta região, a cidade apresenta um imaginário sociocultural fortemente atrelado a uma cosmologia que integra natureza e cultura. "[...], onde o misticismo ligado à cíclica das águas é uma dimensão da potência do imaginário veiculador de mitologias relativas à presença de encantados que circulam por tais paisagens." (SILVEIRA \& SOUZA, 2014, 757).

Situada na Zona do Salgado Paraense, uma importante região econômica do estado, Bragança possui uma vocação natural para a atividade pesqueira e o extrativismo de caranguejos, em especial. Atualmente a pesca, sendo uma das atividades econômicas mais tradicionais na região, representa a maior parcela de contribuição ao PIB no município, o que significa que Bragança é o terceiro maior porto pesqueiro do Estado, com produção industrial e artesanal, sendo esta última a de maior expressividade (SILVA JÚNIOR, 2008).

Sua população está em ascendência, conforme dados apontados pelo Instituto Brasileiro de Geografia e Estatística (IBGE). No último censo de 2010 o município possuía cerca de 113.227 mil habitantes, chegando atualmente a superar, segundo estimativas, a marca dos 120 mil habitantes, constituindo-se, assim, no $9^{\circ}$ município mais populoso do Estado do Pará, segundo dados recentes do IBGE (2014)2. Isto faz com que Bragança seja considerada uma cidade de médio porte na Amazônia Paraense.

Segundo Trindade Júnior (2011) ao analisar a produção de cidades consideradas como médias na Amazônia por conta de sua centralidade diante de outras cidades menores, aponta que o processo de urbanização na Amazônia é marcado por duas fases, sendo a primeira de forma dendrítica, antes de 1960 (atividades econômicas tradicionais; circulação fluvial e ferroviária; cidades pequenas e semelhantes; cidade primaz; concentração econômica; pouco destaque as cidades intermediárias), e a segunda de maneira anastomosada, após 1960 (frentes econômicas e de modernização; circulação multimodal destaque as rodovias; cidades híbridas; difusão do fenômeno de metropolização, desconcentração econômica; importância das cidades médias).

Estas questões são importantes para situar os impasses que residem em classificar Bragança apenas como uma cidade urbana, já que não existem limites

$1 \mathrm{O}$ período em que a pesquisa se deu foi de agosto a novembro de 2013 e teve financiamento da Coordenação de Aperfeiçoamento de Pessoal de Nível Superior (CAPES), sob orientação do Profo Dr. Flávio Leonel Abreu da Silveira (UFPA). Sobre a dissertação Cf. SOUSA SILVA (2015).

2 Para saber mais sobre a cidade de Bragança e seus dados socioeconômicos, consultar o link "Cidades" no site do IBGE, onde também se encontram estimativas populacionais referentes ao ano de 2014, ver link: http://www.ibge.gov.br/home/estatistica/populacao/estimativa2014/estimativa_tcu.shtm; 
rígidos entre o rural e o urbano, o que significa que ambos no contexto da cidade se entrecruzam, criando estilos de vida híbridos.

$\mathrm{Na}$ Amazônia, a dicotomia rural/urbano não ajuda muito a entender os cenários interioranos. Na pesquisa de Silveira e Silva (2014) em uma comunidade rural bragantina, foi percebido o cruzamento da fronteira rural/urbano, por meio da narrativa de Adailton, um de seus interlocutores, quando este se apropria de expressões linguísticas (gírias) próprias ao mundo urbano bragantino. Da mesma forma, Gontijo e Erick (2015) lançam mão do conceito de "interioridade" 3 para pensar a complexidade étnica e cultural dos contextos amazônicos. Os autores discutem que os marcadores de diferença na região estão fortemente imbricados.

Desse modo, as observações e as situações exploradas neste artigo tratam assim da feira livre como um conjunto de espaços complexos, que constituem uma totalidade dinâmica praticada pelos sujeitos que a frequentam, marcada por agências diversas, por vezes conflitantes, diante das experiências vividas com o passar do tempo no corpo citadino, considerando a pluralidade das formas sociais que nela tem assento.

Quando dizemos feira livre, referimo-nos a um espaço mais aberto e heterogêneo de venda e comercialização de produtos (que podem ser materiais e/ou imateriais, a exemplo do comércio sexual, como veremos mais a frente) constituída por lojas consideradas populares e por um ordenamento específico, muito peculiar aos modos de vida bragantinos.

O que nos interessa em meio a esse cenário forjado à beira rio é um espaço mais recente na geografia local, denominado pelos usuários e interlocutores da pesquisa como feirinha, localizado em frente a um Mercado Municipal de Carne (fundado em 1911 no período em que Bragança vivia os resquícios da Belle Époque paraense). É mais propriamente neste local que figuram "homens" 4 que se relacionam - em termos afetivo-sexuais - com pessoas do mesmo sexo e que deambulam à noite.

Situar geograficamente o local da pesquisa é importante. Mapas podem ajudar a entender o contexto do qual se fala e estuda. No entanto, seguindo as reflexões de Akhil Gupta e James Ferguson (2000) quando discutem os "mapas etnográficos", optamos por localizar o campo da pesquisa textualmente. Os autores chamam a atenção para não tratarmos os territórios como grades neutras e fechadas em si mesmos, atrelados a uma cultura nele delimitada. No mundo contemporâneo existem mais que culturas pontilhadas em mapas e identidades aprisionadas em linha imaginadas, pois elas extravasam os limites sejam eles quais forem. Assim, os diferentes espaços que constituem a feira livre se articulam, ou produzem conexões entre si, e isso ocorre em especial pelos deslocamentos que os homens perfazem na medida em que são movidos pelos seus desejos.

\section{O mundo da feira e suas propagações}

3 "[...] um espaço-tempo que transita entre ruralidade e urbanidade, confundido pela dinâmica da etnicidade, em contexto amazônico, nas figuras do caboclo e do ribeirinho, além do indígena e do quilombola. " (GONTIJO \& ERICK, 2015, p. 31).

$4 \mathrm{O}$ termo está aspado, pois, conforme veremos os sujeitos participantes dessa pesquisa se identificam multiplamente, incluindo identidades trans. Neste contexto, homem pode designar o exercício da masculinidade com todas as suas representações. Sendo assim, alguns apesar de adotarem performances femininas (bichas afeminadas) se assumem como homens, enquanto que existem travestis que se identificam como "mocinha", "menina" e outras que apesar de exercerem a performance feminina se assumem biologicamente homem. 
O lugar do qual falamos é marcado pela efervescência do tempo e pelo fluxo constante de transeuntes. Como lugar de trânsito e de passagem, ela reflete a efemeridade do mundo moderno, assim como também está marcada pela permanência dos possíveis encontros nela tidos; pelo estabelecimento de relações amistosas entre os seus trabalhadores e outros sujeitos que nela circulam. Ao compartilharem de um mesmo lugar as pessoas se apropriam simbolicamente dos espaços da feira, experimentando os códigos e as regras que seriam próprias as suas práticas coletivas.

A partir da e na feira podem se constituir as formas sociais, consideradas por Simmel (1983a) como o resultado da reciprocidade consciente5 da ação de sujeitos, cujas tramas de relações poderão ser mais ou menos efêmeras, ou contrariamente, podem produzir vínculos que se prolongarão dependendo dos laços ali gerados. Seria assim, também, o espaço de conflito/negociação, e isso é importante para entendermos a profusão de sentidos e intencionalidades entre aqueles que vão à feira com o intuito de praticá-la cotidianamente, conforme aponta Viviane Vedana (2013) ao pensar o "fazer a feira" como uma via de mão dupla.

Os deslocamentos e a efervescência das trocas são as dinâmicas sociais que deixam suas impressões mais visíveis a quem observa o local, e eles seriam percebidos tanto nos períodos diurnos - quando o fluxo de pessoas é mais intenso - quanto no período noturno, quando o fluxo menor de pessoas cria novas territorialidades e novos trajetos vinculados à procura de bens e serviços diferentes daqueles obtidos nos períodos do dia.

Estas apresentações são necessárias para compreendermos em que cenário homens que possuem vivências afetivas e sexuais com pessoas do mesmo sexo estão inseridos, tendo em vista que a referência neste trabalho e na pesquisa como um todo, não é a "cidade-metrópole" 6 . O ponto de partida é uma cidade que apresenta um cotidiano ainda marcado por regimes de província, cuja população ainda beira os 120 mil habitantes.

Além disso, apresentar as nuances dos modos como a feira está organizada é também uma possibilidade de compreender, ao mesmo tempo, que ela é um espaço de agência, de confluência de interesses, e que como resultado desse acionamento, há mudanças e transformações atreladas, projetadas cotidianamente pelo coletivo.

Portanto, ao longo da pesquisa várias transformações de ordem social, física, política e econômica foram observadas. Quando do início da pesquisa em agosto de 2013, a feira já havia passado por um ciclo de reorganização espacial que se iniciou com os projetos de melhoramentos urbanos na segunda metade do século XX. Até 2013, a cronologia histórica de intervenções no espaço da feira livre termina com a interdição do Mercado Municipal de Carne para fins de

5 Para Georg Simmel (1983b) a noção e sociação designa a forma "pela qual os indivíduos se agrupam em unidades que satisfazem seus interesses." (p. 166).

6 Há uma expressiva quantidade de trabalhos que tem enfocado os espaços de sociabilidade de homens com práticas homossexuais no Brasil, cujo campo de investigação é a metrópole ou as cidades pertencentes a regiões metropolitanas. A presente pesquisa questiona e buscou compreender as redes de sociabilidades em um cenário que possui uma especificidade marcadamente regional, o que por si só já é um desafio. O universo urbano na Amazônia se diferencia no que tange a produção de espaços de sociabilidade. Isso não significa que não há articulação de lugares na Amazônia, e destes com outras regiões dentro e fora do país, desde processos de globalização cultural e econômica. Isso é muito claro, se compreendermos o fluxo crescente de travestis e jovens homossexuais que se deslocam de cidades amazônicas para outras regiões do Brasil, em especial Goiânia e São Paulo para se iniciarem na experiência da prostituição. Pelo contrário, em tempos de globalização acelerada, pensar a articulação entre o local e o global, significa situar um "jogocultura" (Gupta \& Ferguson, 2000) em que as fronteiras estão sendo cada vez mais borradas (centro/periferia, colônia/metrópole) e onde as identidades estão cada vez mais (des)territorializadas. 
restauração no final de 2011. Isso provocou uma reorganização no espaço local, pois o mercado abrigava vários comerciantes, interna e externamente, o que fez com que estes passassem a se reordenar em outros logradouros, dentre eles, a feirinha. Além disso, as esquinas do mercado serviam como ponto de encontro e de prostituição para travestis e homossexuais no período noturno.

Então, as mudanças provocadas por essas intervenções urbanas no espaço da feira foram acompanhadas em boa parte, também, por um reordenamento erótico. Na cronologia temporal da homossociabilidade na feira livre houve diversas mudanças em relação aos pontos de encontro. Historicamente, os sujeitos com práticas homoeróticas, começaram a se encontrar, segundo algumas narrativas colhidas durante o trabalho de campo, em meados da década de 70, quando muitos ainda eram estudantes secundaristas. Terminadas as aulas "desciam"7 até o cais do porto para "tomar uma" (em referência a ingestão de bebidas alcoólicas). Neste lugar já existia uma zona de meretrício composta de bares, onde várias mulheres se prostituíam e atendiam principalmente trabalhadores da pesca, conhecidos popularmente como "pirangueiros".

\section{As Personagens de uma trama erótica}

A pesquisa contou ao longo do seu desenvolvimento com vários interlocutores, que eram abordados nas mais diversas situações. Com estes obtivemos muitas informações e detalhes dos processos observados. Isto significa que grande parte dos dados coletados foram obtidos através de conversas informais.

A todo foram concedidas 06 entrevistas abertas com personagens diferentes, todas decorridas de um processo anterior de conversa e de conquista de confiança. As entrevistas foram realizadas no espaço/tempo onde a pesquisa se deu. Por se tratar de um lugar liminar e "marginal", aos moldes de Perlongher (2008), as anotações e o uso do gravador causavam desconforto, o que impediu a concessão de outras entrevistas.

Desse modo, as pessoas que aparecem na pesquisa por meio de suas narrativas foram aquelas que mais colaboraram para o entendimento dos fenômenos sociais ali gestados, ajudando a compreender as situações observadas. Por isso, apresentamos: Shanna (47 anos), Durval (48 anos), Estefanny (21 anos), Raquel (27 anos), Brunete (16 anos) e Sasha (25 anos).

Os nomes apregoados são fictícios e dialogam com as identidades de gênero dos sujeitos participantes. Grande parte dos homossexuais e travestis que frequentavam a feirinha tinha um codinome feminino, um nome de "guerra", o que neste contexto se torna mais usual. Daí a escolha na pesquisa por outros nomes. De modo geral, Estefanny, Raquel, Brunete e Sasha, consideravam-se travestis, identidade de gênero que as acompanha desde a mais tenra idade, enquanto Shanna e Durval, consideravam-se homens, apesar de burlarem em suas corporalidades e linguagens, as fronteiras entre o masculino e o feminino.

Em geral, boa parte da trajetória de vida desses sujeitos é marcada por questões de violências físicas e simbólicas, devido suas identidades e

7 Popularmente em Bragança, usa-se a expressão "ir lá em baixo" para se referir a zona comercial do município, mais precisamente a feira livre a beira rio. 
performances de gênero. Todos de algum modo pertencem a redes de sociabilidades iguais ou próximas, o que significa que estabelecem relações em outros contextos. Com exceção de Durval, todos os sujeitos citados ainda são frequentadores da feirinha, regulando suas idas numa espécie de contrato grupal.

No enredo desta trama, segue as apresentações dos personagens principais:

Estefanny foi a principal intermediadora na entrada em campo e no contato com as pessoas que frequentavam a feirinha. Por diversas, era ela quem revelava os lugares de encontro, os habitués (principalmente os homens, considerados heteros, que procuravam na feirinha uma experiência erótica e sexual), os esquemas eróticos, a moralidade que ali se estabelecia (em especial, os esquemas ilícitos), assim como, as agruras, ou seja, os cuidados necessários para permanecer no local.

No tocante, Shanna e Durval se conhecem desde longos anos, compartilhando diversas experiências comuns, entre elas, a frequência na feira em tempos áureos quando jovens. Ambos, exercem ocupações comuns, trabalhando como cozinheira(o), diarista, costureiro(a), o que demarca o campo de atuação profissional para aqueles que assumem uma identidade LGBT8, e que pertencem as camadas populares interioranas.

Raquel e Sasha são irmãs biológicas e ambas assumem a identidade travesti. Filhas de mãe solteira, negra e doméstica, moraram com a mãe até metade da adolescência, quando esta as expulsou de casa depois que ambas assumiram suas identidades de gênero. Após o falecimento da mãe por consequências do HIV/AIDS, cada uma procurou seus próprios caminhos. Até o final da pesquisa, Raquel estava envolvida em situações de tráfico de drogas, e Sasha teria se envolvido no tráfico internacional de pessoas, onde teria ido para a Itália fazer programa. Tempos mais tarde Sasha é assassinada numa cidade no leste italiano.

E por fim, Brunete, a mais jovem entre as interlocutoras. No início da pesquisa, era estudante de uma escola pública e morava com a avó, tios e primos numa casa situada num bairro distante da feirinha. Segundo ela, sua família sabia que realizava programas sexuais na feira livre da cidade e que com a renda participava do orçamento familiar, ajudando na criação de sua irmã mais nova. Atualmente, ela reside em São Paulo onde se prostitui junto com outras travestis bragantinas.

Feita esta breve apresentação sobre o percurso de vida das interlocutoras da pesquisa, o presente artigo buscará apresentar a fluência dos desejos construídos a partir da vivência na feirinha, tomando como foco de análise, em especial, a entrevista realizada com Durval, pois é ele quem retrata de maneira mais detalhada os elementos que confluíram para que a feirinha se tornasse um espaço de exercício da sexualidade. Alinhada a narrativa de Durval, também serão expostas algumas descrições contidas no caderno de campo.

\section{A efervescência do desejo nas memórias de Durval}


Durval (48 anos) é um homem de meia idade, cujo corpo tomado de tatuagens, expressa as suas mais diferentes experiências, inclusive amorosas, já que algumas são escritos dos nomes de antigos namorados. Em seu corpo há indícios de relações tensas, expressas por cicatrizes vivas deixadas pelo tempo. Atualmente, trabalha com a mãe que é costureira, mas boa parte da sua vida trabalhou como cozinheiro e diarista. Apesar de não frequentar mais o ambiente da feira, o contato com Durval se deu através de conversa com outros interlocutores. Ao relatar sobre as paisagens que compunham o cenário na época que começou a frequentar o espaço, mergulha nas suas memórias e lembra aquilo que chama de sua "época de ouro", um momento marcado pela jovialidade e pelo frenesi.

Durval - Olha nos anos 70 quando eu habitei naquela feira não tinha aquela feirinha ali. Ali já existia o posto fiscal, né? Ao lado do posto fiscal tinha assim um... uma cerca e tinha um camburão grande que era onde depositava os óleos pra embarcações pegar. Ai, tinha o chalé [...] já tinha aquela feirinha de peixe seco, $e$ tinha também, já tinha dava algum, algumas garotas de programa, os garotos de programa, lá pelo meio da feira, mais o nosso point mesmo era na calçada do posto fiscal. Daí, foi quando já surgiu a feirinha, a da beira da maré, da orla, né?

Pesquisador - Que é onde elas estão agora?

Durval - Não, não. É aquela feirinha descendo o Rex Bar, que ali agora só é ponto comercial, né? É negócio de embarcação, banca de revista, mas antigamente ali só era bar. Tinha o bar da Lulu, que é único bar quềda [que ainda] sobrevive é o da Lulu.

$P$ - Que também era ponto de encontro?

D - Ponto de encontro. Tinha também o bar do seu Riba, o bar da Lourdes, o bar da Lúcia, o bar da Edna, e vários bar. Então ali que a gente se encontrava. A gente se encontrava ali, e como sempre a gente dava um jeitinho, né? Não tinha aquela orla da beira da maré não tinha, que sai agora pela beira que a gente vai sair lá na geleira, né? Ali não tinha. Ali era um matagal. Um matagal muito feio. Ai já pelos anos 80 , pelos anos 90 , foram abrindo.

(Entrevista realizada em 26/o3/2014)9

A relação entre a área portuária e a prostituição é recorrente na história. Por ser uma área de intensa movimentação, o porto se constitui, em contextos amazônicos ribeirinhos, como o principal local de expressão da sociabilidade masculina, marcado pelo êxtase do ir e do vir. Nestes contextos, o bar, a bebida e a "camaradagem" tem a função social de "aliviar" as tensões expressas pelo trabalho da pesca.

Desse modo, quando a pesquisa foi realizada o cenário da feirinha, lócus privilegiado das observações, assim se apresentava: O som em volume alto se destaca em meio ao silêncio noturno da feira, ambiente reconhecido pelo barulho e pela intensa movimentação. A noite imprime outros movimentos ao local. O som vindo de bares que ficam atrás das barracas de madeira convida um público diferenciado a adentrar por entre as suas vielas, ou por trás de um posto fiscal portuário (local que abrigava também a AFEAB10), que fica em suas mediações. As pessoas chegam a pé, de bicicleta ou de mototáxi.

Os bares, construídos em palafitas, margeiam o rio Caeté e se tornam locais de recepção para aqueles que chegam do alto-mar. Assim, o movimento festivo da noite alcança seu ponto mais denso quando da chegada dos 
pescadores provenientes de viagens que duram de quinze a trinta dias. Ao aportem em terras firmes da pequena cidade, chegam sedentos de festas, lazer, alívio e desejo, portanto encontram nos bares os lugares ideais para comemorarem o curto tempo (não mais que uma semana, quando a pesca está boa) em que ficam desembarcados até retornarem novamente para mais uma jornada de trabalho. Assim, fica claro o que Maffesoli (2007: 06, 02, respectivamente) chama de a "revanche do dionisíaco" na vida social, ou o "retorno do princípio de Eros". O orgíaco dimensiona as relações no espaço estruturando os modos de operá-las, conforme elas se estabelecem.

Ao todo são quinze os bares alinhados um ao lado do outro, sendo uns menores que outros, em que mulheres, em sua maioria, homossexuais e travestis são as/os responsáveis por seu gerenciamento. São estas que providenciam a bebida e as possíveis acompanhantes para os [homens] que chegam. Existem alguns nomes de estabelecimentos interessantes, como: "Bar Delas", "Barraca da Morena" e "Barraca da Bacana", que dizem de certa forma, o perfil feminino da recepção.

Ainda sobre a narrativa de Durval, destaca-se um lugar denominado como chalé que se referia a um prostíbulo localizado na zona portuária e comercial de Bragança11. Em outro momento de sua entrevista Durval comenta que no chalé havia a participação de homossexuais nos arranjos dos programas para as mapôs (em referência as mulheres prostitutas, neste caso), conforme afirma:

\begin{abstract}
Pesquisador - E quem conseguia geralmente os boys eram as bichas? 12
Durval - Era... a maioria era. Porque as vezes os bofe chegavam, não conheciam as mapô né? Aí a gente já era puta velha lá, veterana lá, aí ele dava uma cerveja pra gente fazer a cabeça das mulher..
\end{abstract}

A partir da narrativa de Durval é possível perceber outros pontos no mapa da homossociabilidade em Bragança, entre eles: As calçadas de um posto fiscal que ficava próximo ao cais do porto. Depois, numa sequência meramente didática, há a referência a um comércio denominado Poço de Jacó, que era um restaurante que ficava aberto até altas horas da madrugada. Próximo dali, emerge a sociabilidade no meio fio da Praça da República, caracterizada pela expressiva figura da travesti nestes meios. Posteriormente, acontece uma intervenção de melhoramento urbano na Praça da República e ocorre a migração da sociabilidade homoerótica para a esquina do Mercado de Carne, conforme já referido, e por fim, como último paradeiro desta viagem libidinal encontra-se a feirinha.

Pensar estes pontos não significa dizer que há uma linearidade no percurso da sociabilidade homoerótica em Bragança. Existem referências dos deslocamentos por onde ela perpassou, o que não significa que a medida que migrava de um local para outro, a frequência ao local anterior acabava. Ao contrário, à medida que esses deslocamentos ocorriam, o grupo se recompunha, e se reajustava internamente mediante algumas tensões e desacordos com a própria constituição deste novo grupo.

Como parte da vida vivida, estes lugares estão impregnados no imaginário social e cultural da cidade, e permeiam as memórias dos seus habitués. Ao ser

11 Em Belém (PA), por exemplo, os lugares inscritos no chamado circuito GLS, em sua maioria, estão situados em zonas de comércio sexual, sejam boates, bares, saunas e cinemas.

12 Bicha é uma categoria nativa, popularmente usada nos contextos de sociabilidade homossexual, com forte conotação política e identitária. 
perguntado sobre suas vivências e motivações de ida à feira, Durval expõe o imperativo do desejo e do prazer de um "tempo-foi"13:

\begin{abstract}
Durval - Ah bicha! Ali eram os pescador quando chegavam. Os pescador quando chegavam naquela época não tinha as ploc14 né? Não tinha não! Não tinha. As mulheres não, porque as mulheres tinham que ir lá pros cabaré, pro Pitinga, pro Jacaré, pro Amor do Céu, pra Zenaide, pra Lurdinha, era pra onde elas iam né? Aonde elas frequentavam. Era os ponto delas. Então ali só dava bicha mesmo. O que marcava naquela época era quando chegava um barco. Que quando chegava um barco, porque a coisa tava boa mermo, tinha noite da gente fazer até seis... oito programa e as bichas faziam. Elas tinham que fazer, porque eles [os pescadores] levavam pelo braço. Não tinha esse negócio de dizer "umbora, umbora". Não! Era levada pelo braço. Não tinha essa dificuldade de maneira nenhuma não, porque levava pelo braço. Era! Não tinha esse negócio. Logo ali, era menos frequentado do que é hoje. Era assim, um ponto escuro. Só tinha ali debaixo do chalé, o cara que vendia comida, o [...] como era o nome dele meu Deus? [...] um coroa que já até morreu, que vendia comida lá? Só era ali onde dava mais gente. Aquele resto ali era escuro [em referência onde hoje está a feirinha]. Era escuro mesmo! Aí, quando eles chegavam, que eles avistavam assim, umas quatro, cinco, eles voavam em cima $e$ levavam mesmo. Não tinha como. A gente ainda ia botando o corpete. Era levada. Eu me lembro assim, d'uma noite, em que eu e o finado "Risada" - que Deus tenha ele em um bom lugar - a gente fez uma disputa pra ver quem dava mais. A gente deu oito vez cada uma. Oito! Porque não tinha como? Era a gente ir chegando... Era... Era.

Olha, não tinha essa epidemia de doença que tem hoje também. Tem mais isso, não tinha! Não tinha esse negócio de gangue. Não tinha esses malandro que rolam lá pela beira. Droga não existia esse negócio de nóia, pra deixar os cara alucinado pra fazer maldade com a gente. Não existia. O que existia por ali era uma maconhazinha que a galera fumava, só isso. O resto era cachaça mesmo, só cachaça mesmo que rolava.
\end{abstract}

As memórias de Durval evocam as tramas de uma sociedade que se organiza e se mantém na penumbra, nos vazios recônditos de onde se ouvem murmurinhos ou silêncios disfarçados de namorados que fogem da vigilância à procura de refúgios sombrios. Isso só era possível, porque o escuro assumia naquele contexto uma posição central, o disfarce. Além de evocar imagens libidinosas, o escuro era em si, o lugar da recepção dos desejos desviantes.

Dessa forma, a feira como lugar praticado noturnamente, expressava uma ambiguidade, já que era ao mesmo tempo, o lugar escolhido, a terra prometida por onde emanava correntes libidinais eufóricas, e em contrapartida, ou talvez em confluência, era o lugar a ser destinado toda prática de caráter transgressivo cujo selo é a "marginalidade".

Nesse sentido, acabamos percebendo que havia um discurso moral, que (des)legitimava a feira e os sujeitos que dela faziam uso cotidiano à noite, e ao fazer isso, os realocavam numa posição marginal, mesmo que este lugar estivesse no "centro" da cidade. Uma série de regras sociais havia espacializado lugares dignos e indignos de sociabilidades, impregnando-os de valores socialmente acordados pela sociedade bragantina.15

A pesquisa realizada por Néstor Perlongher (1987) entre michês e seus clientes no centro urbano de uma grande cidade - "a metrópole" -, demonstra

13 Expressão poética emprestada de Afredo Gracia Bragança, escritor paraense.

14 Ploc é um termo popular que designa mulher envolvida na prostituição. Faz referência a um tipo de chiclete comercializado entre os vendedores de rua.

15 A discussão sobre centro e periferia tem sido superada na antropologia urbana (existem esforços para isso, cf. Gupta e Ferguson (2000) ao questionar a relação território-cultura como fixa por meio da análise dos que vivem na fronteira e que não reivindicam territórios fixos e nem fixação a um determinado lugar). Ao se discutir o campo marginal de determinadas espacialidades, pretende-se, neste trabalho: compreendê-las como marcações atribuídas discursivamente num jogo de poder estrutural; questionar os limites entre lugares dignos e indignos de sociabilidade, compreendendo que as centralidades são muito mais simbólicas do que físicas. 
como a noite sugere errâncias, ou modos conscientes de se perder nos (des)caminhos na/da cidade. É por essa razão que o poeta e antropólogo argentino, que conviveu entre os michês e outros sujeitos "marginais"16 por mais de três anos, preocupa-se teoricamente em compreender as perambulações, os deslocamentos de tais sujeitos, numa tentativa de alinhar uma antropologia da e na cidade, vista de dentro. Nesse sentido, o antropólogo Hélio Silva aponta que: "O conhecimento da cidade, é portanto, um conhecimento produzido pelos percursos. [de modo que a cidade deve ser vista] do interior de suas entranhas." (2009: 174, grifo nosso).

Sendo assim, a noite produz seus próprios espaços, desterritorializando e reterritorializando os sujeitos diante de suas deambulações, num fluxo de pessoas e devires que é o de produção de sentidos de vivê-la em sua intensidade desejante. Estes dois processos foram também discutidos por Perlongher (1987) e Margulis (1997), cujas inspirações residem em Jean Baudrillard, para quem não se pode pensar o social sem antes pensar o desejo.

\section{A noite produz seus próprios espaços: derivas e (re)organização de territorialidades}

No decorrer da pesquisa empreendida, o tempo da noite se tornou o lugar de morada dos silêncios e dos prazeres, assim como do perigo e do incognoscível. De acordo com o sociólogo argentino Mário Margulis, a noite configura outra cidade, com personagens que fogem do controle e da regulação do cotidiano. Sendo assim, ela constrói regras na contra-ordem "[...] con la conciencia menos vigilante, adormecida por el sueño.” (1997: 15).

Desse modo, a noite assumiria um tempo propício à festa. $\mathrm{O}$ caráter festivo da noite sugere o consumo, e a festa assume um lugar de importância no imaginário urbano (CERTEAU, 1993): "En el tiempo y el espacio de la fiesta fluyen condiciones para que emerjan otras características de lo festivo: la liberdad, la rebelión, la subversión de los poderes, el goce, la imaginación, el extásis." (MARGULIS, 1997: 16). Estas questões justificam os motivos pelos quais os bares que se localizavam a beira rio e tornavam centros polarizadores de gente.

A sociabilidade que emergia do espaço da feirinha era imersa no universo obscuro e arisco da noite. Por isso, perambular na noite e vivenciar o que Mário Margulis chama de nocturnidad (1997) exigia o exercício de um espírito sensível envolvendo as errâncias de corpos que vagam pelos meandros dos lugares (JACQUES, 2006). Aos modos sugeridos por Colette Pétonett,(1982 [2008]), a partir da observação flutuante, deambulava-se nos caminhos estreitos entre as barracas de madeira que compunham o espaço da feirinha, a procura de pista para compreender os significados do "estar lá".

Assim, mover-se pela experiência errante e percorrer a feira, suas externalidades e interioridades, observando suas mais diversas facetas ocultas, vislumbrando aquilo que Perlongher (2005 [1988]) chamou da "obsessiva rotulação" que impera em meios vistos como marginais, é uma possibilidade metodológica de se fazer pesquisas no urbano, em contextos não-hegemônicos (PÉTONETT, 1982 [2008]). O que esperávamos desse andar desvairado pela 
"calada da noite"17 na feira, era a compreensão de uma dinâmica obscurecida, mascarada pelas rotulações que aquele lugar recebia.

Para ilustrar estas questões, destacamos um trecho do diário de campo ocorrido no dia 23 de agosto de 2013, quando ainda nas primeiras observações se presenciou a articulação de um "esquema”, uma espécie de jogo erótico de conquista entre a bicha e o bofe (categorias analíticas usadas na pesquisa).

A feirinha se situa numa região a beira rio, de frente para um mercado municipal já citado, separado apenas por uma rua de intenso tráfego, denominada rua dos pirangas, em referência a figura do pescador. Na esquina desse mercado hoje interditado para fins de restauração, há um ponto de táxi que durante a noite com o avançar das horas se torna um vazio urbano. Por ser escuro, facilitava determinados encontros e se tornou no início da pesquisa um ponto de observação estratégico. De lá se observou a seguinte situação:

\begin{abstract}
"Avista-se saindo das barracas um rapaz que na noite do dia 16/o8/2013, numa sexta-feira, tinha sido visto transitando no espaço da feira. Conversava com Lilica dizendo que eu [Cássio] o conhecia e que o achava bonito. Ela me diz que vinha frequentemente ao local e que ficava dando em cima das bichas. Fiquei impressionado já que ele era marido de uma amiga minha.

Decorrido certo tempo, vejo novamente este rapaz. Ele passa na rua e adentra novamente pelas barracas. Uma bicha não conhecida desce pela rua a minha esquerda e também adentra a feirinha. Momentos depois, o dito rapaz, sai desconfiado e sobe pela mesma rua. Logo depois, a bicha que acabara de chegar também segue o mesmo rumo. Percebo que seja um momento interessante para acompanhar uma linha18 entre uma bicha e um boy. Saio do ponto de táxi e sigo atrás de ambos disfarçadamente. Ambos estavam em lados opostos da rua. Não sabia exatamente para onde estavam indo. Provavelmente seria ele quem indicaria o local, já que estava na frente. Como forma de não levantar suspeita, dobro numa rua paralela a fim de encontrá-los mais a frente, mas isso não acontece. Ambos sumiram. Ainda andei por ruas próximas, mas não os encontrei. A tentativa era compreender quais seriam os locais escolhidos para a realização de tais encontros. Dessa forma, acabei não retornando para a feirinha e encerrar a pesquisa do dia por ali mesmo. Isso já era por volta das 21:3oh. No outro dia, na feira encontro a dita bicha, personagem do esquema, que me confessa ter naquela noite passado (termo que significa ter relação sexual com ou sem penetração) seis boys. Resolvo perguntar sobre o tal rapaz, e responde dizendo que tinha ido com ele para o Mâncio.”
\end{abstract}

A situação acima destacada é elucidativa, na medida em que revela alguns aspectos do cotidiano investigado: 1) As redes sociais são proximais, o que significa que há um reconhecimento de quem faz ou não parte daquele métier. Além disso, as mesmas pessoas que frequentavam aquele ambiente se encontravam em outros lugares da cidade e pertenciam a outros grupos sociais comuns. 2) $\mathrm{O}$ contato interpessoal com finalidades sexuais se utilizava mais de códigos e expressões corporais do que propriamente de discursos, o que significa que os comandos eram sinalizados, na maioria das vezes, pelos olhos, boca e mãos. 3) Os boys que frequentavam o local eram geralmente homens, pescadores, em sua maioria na faixa etária entre 30-40 anos, e que já se relacionava com alguma das bichas que ali frequentavam.

No relato acima, surge uma personagem que não compõe o quadro de entrevistadas, mas que configurava cotidianamente o cenário da feirinha.

17 Esta expressão é muito usual no dialeto local, que simboliza em muito as perambulações silenciosas e intencionais de sujeitos à procura de sexo casual no espaço urbano: os rastros de sombras que se deslocam de um local para outro apressadamente. Rastros que se perdem nos escuros das barracas de madeira.

18 Entre os/as interlocutores/interlocutoras, fazer a linha designa participar de um esquema, seja ele, erótico ou não. Seria organizar algum modo de relação entre pessoas. 
Nomeada a partir de um pseudônimo feminino19, Lilica frequenta o local desde que era adolescente. Sobrinha de Shanna, sua intermediadora, Lilica construiu seu círculo de amizades a partir da feira. Nas diversas vezes que conversamos, ela relatava situações de conflitos entre o grupo de homossexuais e outros habitués da feirinha. Outrossim, também comentava sobre as dinâmicas eróticas que envolviam os encontros e os lugares que usava para ter suas relações sexuais. No entanto, assim como muitos, ela tinha receio de dá entrevista, já que neste meio a desconfiança é um valor aprendido a duras penas.

Durante as observações de campo e a partir das indicações de Lilica e outras pessoas, houve também o mapeamento dos possíveis espaços onde aconteciam os encontros sexuais. Além dos vazios e escuros da feira, outros "vazios" urbanos eram ocupados para estes fins. Havia um circuito de espaços próximos da feira que eram percorridos durante a noite, entre eles: casarões antigos abandonados, a exemplo do Mâncio referido no trecho acima; casas em construção, quintais abertos onde uma vegetação rasteira predomina, pontos escuros e recônditos, entre outros.

Havia também lugares onde se pagava a custos menores que motéis, usados para sexo, e que ficam próximos à feira. Estes lugares se tornavam pouco conhecidos, a não ser quando se participava como integrante dos contextos relatados, pois eles eram camuflados na paisagem urbana, sob o pretexto de serem casas residenciais.

No entanto, "qualquer lugar, é lugar!" disse uma de minhas interlocutoras. Qualquer lugar que sugira certa privacidade, depois da meia noite, torna-se propício a encontros, até mesmo a rua pode ser um cenário para uma felação rápida e casual.

A busca por outros refúgios para o prazer, além da feira, devia-se ao fato de haver vigias, responsáveis por zelar as barracas e mercadorias dos feirantes, que coibiam tais atos, sendo que em casos de flagrantes, havia uma repressão violenta por parte de tais vigilantes, por meio de agressões físicas com a utilização de cassetetes que carregam consigo. Portanto, ao buscarem outros refúgios os personagens dessa trama erótica, criavam/criam, assim, outros espaços atribuindo a eles sentidos no contra-uso, resignificando a cidade, forjando assim, uma geografia dos prazeres.

\section{Considerações finais}

Ao longo deste artigo foi possível vislumbrar contextos produzidos pelo exercício do desejo, tomando a busca por vivências afetivas e sexuais entre pessoas do mesmo sexo, como propulsora da construção de outros espaços e de outra cidade. Ao fazerem da feira um "lugar praticado" (CERTEAU, 1993) o grupo reivindicava a conformação de um espaço legítimo da vivência homoerótica, no qual a frequência regular ao local se configurava como a principal arma política.

$19 \mathrm{Na}$ pesquisa os nomes originais dos interlocutores e das interlocutoras foram preservados. No entanto, os nomes fictícios que se apresentam neste trabalho fazem parte do imaginário investigado. Boa parte dos sujeitos da pesquisa ao fazerem referência ao seu "nome de guerra", utilizava-se de um codinome feminino. Quando da ausência destes nomes, usava-se outras expressões que remetiam o homossexual a uma condição feminina, a exemplo o próprio termo bicha. 
No entanto, é cabível salientar que apesar destas elucidações, a feira não se constitui num ambiente, exclusivamente, gay, aos moldes do que se estrutura em outros espaços, como boates e bares, destinados a um público específico. Ao contrário, a feira, assim como muitos outros espaços urbanos de cidades interioranas no Pará, é compartilhada por outros sujeitos. Há sim, locais de encontros e de frequência onde há uma predominância de pessoas com desejos e interesses voltados àqueles do mesmo sexo, em especial a de homens que se relacionam afetivo-sexualmente com outros homens.

Atualmente, o cenário vislumbrado por esta pesquisa sofreu outras mudanças, decorridas de um projeto de revitalização da orla e da beira rio da cidade de Bragança, que removeu daquele espaço geográfico a feirinha, lugar privilegiado de nossas observações. Isso redirecionou a sociabilidade ali instaurada, já que tantos as barracas de madeira, quanto os bares em palafita, foram removidos da paisagem local.

Por fim, fazemos um adentro quanto o uso das categorias analíticas - bicha e bofe ou boy empregadas neste trabalho. "Bicha" era o termo de tratamento mais usual entre as interlocutoras e interlocutores desta pesquisa. Por vezes o termo se configurava numa saudação, quando da chegada ao local e no encontro com outras bichas. Em outras ocasiões se tornava um modo prático e eficaz de estabelecer relações amistosas com as outras pessoas participantes daquele contexto.

A aderência por este termo se deve por acreditarmos que ele carrega consigo linguagens, discursos e modos de organização que retratam a lógica que se esconde por trás das pejorações que costumeiramente estão associados a ele. Sendo assim, os sujeitos se apoderam dele discursivamente, esvaziando-o de toda carga pejorativa (acusatório) que lhe é empregado.

Ademais por se tratar de uma categoria nativa (expressão de uso corriqueiro), que o grupo se apropriou de modo diferenciado, acreditamos que "bicha" se assenta num modelo de sexualidade, em que as hierárquicas já não são tão rígidas, havendo assim, os deslocamentos e a fluidez identitária. Seria, então, uma categoria coletiva que nomeia e constrói corpos e pessoas.

\section{Referências Bibliográficas}

CERTEAU, Michel de. La culture au pluriel. Éditions du Seuil, 1993.

GONTIJO, Fabiano \& ERICK, Igor. Diversidade sexual e de gênero, ruralidade, interioridade e etnicidade no Brasil: ausências, silenciamentos e exortações. Aceno, v. 2, n. 4, ago/dez. 2015, p. 24-40.

GUPTA, Akhil \& FERGUSON, James. Mais além da "cultura": espaço, identidade e política da diferença. In: ARANTES, Antônio A. (org). O espaço da diferença. Campinas: Papirus, 2000, pp. 30-49.

JACQUES, Paola B. Elogio aos errantes: a arte de se perder na cidade. In: JEUDY, Henri P. e JACQUES, Paola. B. (Orgs.) Corpos e cenários urbanos. Salvador: EdUFBA, 2006, pp. 117-139. 
MAFFESOLI, Michel. Homossociabilidade: da identidade às identificações. Bagoas: Revista de Estudos gays e lésbicos, Natal-RN, v.1, n.1, jul./dez. 2007, p. 15-26.

MARGULIS, Mario. La cultura de la noche. In: La Cultura de la noche: La vida nocturna de los jóvenes en Buenos Aires. Biblios, Argentina, 1997, p. 11-30.

PERLONGHER, Néstor. O negócio do michê. A prostituição viril em São Paulo. Fundação Perseu Abramo, 2008(1987).

PERLONGHER, Néstor. Territórios Marginais. In: GREEN, James N. \& TRINDADE, Ronaldo. Homossexualismo em São Paulo e outros escritos. São Paulo: Editora UNESP, 2005 (1988), pp. 263-290.

PÉTONETT, Colette. Observação Flutuante - um exemplo de um cemitério parisiense. Antropolítica, Niterói, n. 25, 2008, pp. 99-111.

SILVA JÚNIOR, Sebastião Rodrigues. A pesca Artesanal $e$ o fundo constitucional do norte: um estudo sobre o financiamento concedido aos pescadores artesanais da região bragantina. Dissertação de Mestrado. Biologia Ambiental, UPFA, 2008.

SILVA, Hélio R. S. A situação etnográfica: andar e ver. Horizontes Antropológicos, Porto Alegre, 15(32), 2009, p. 171-188.

SILVEIRA, Flávio Leonel Abreu \& SOUZA, Camilla da Silva. Imaginário, trabalho e sexualidade entre os coletores de caranguejo do salgado paraense. Revista Estudos Feministas, Florianópolis, 22 (3), 2014, p. 755-780.

SIMMEL, Georg. Como as formas sociais se mantêm. In: MORAES FILHO, Evaristo de (org.). Georg Simmel. (Coleção Sociologia). São Paulo: Ed. Ática, 1983a, pp. 46-58.

SIMMEL, Georg. Sociabilidade - um exemplo de sociologia pura ou formal. In: MORAES FILHO, Evaristo de (org.). Georg Simmel. (Coleção Sociologia). São Paulo: Ed. Ática, 1983b, pp. 165-181.

SOUSA SILVA, Cássio José de. O "alivio" incontido: êxtase, desejo e sexualidade em uma feira livre, Bragança-PA. Dissertação de Mestrado, PPGLSA, UFPA, 2015.

TRINDADE JÚNIOR, Saint-Clair. Cidades média na Amazônia Oriental: Das novas centralidades à fragmentação do território. Estudos Urbanos e Regionais, v. 13, n. 2, 2011, p.135-151.

VEDANA, Viviane. Fazer a feira e ser feirante - construção cotidiana do trabalho em mercados de rua. Horizontes Antropológicos, Porto Alegre, ano 19, n. 39, jan./jun. 2013, p. 41-68. 